\title{
HUBUNGAN ANTARA ASPEK-ASPEK PENGONTROLAN DIRI DENGAN PERILAKU SEKSUAL PADA GAY DI WILAYAH KOTA BAU-BAU PROVINSI SULAWESI TENGGARA
}

\section{RELATIONSHIP BETWEEN ASPECTS OF SELF CONTROL WITH SEXUAL BEHAVIOR IN GAY URBAN IN BAU-BAU SOUTH EAST SULAWESI}

\author{
${ }^{1}$ Sri Hertati Endang, ${ }^{2}$ Arifin Seweng, ${ }^{3}$ Andi Mardiah Tahir \\ ${ }^{1}$ Bagian Kesehatan Reproduksi, Fakultas Kesehatan Masyarakat, Universitas Hasanuddin, \\ ${ }^{2}$ Bagian Biostatistik, Fakultas Kesehatan Masyarakat, Universitas Hasanuddin \\ ${ }^{3}$ Bagian $O B G Y N$, Fakultas Kedokteran, Universitas Hasanuddin,
}

\begin{abstract}
Alamat Korespondensi : $\quad$ Sri Hertati Endang, Fakultas Kesehatan Masyarakat Universitas Hasanuddin, Makassar, 90245, HP : 081354563167

Email : Srihertatiendang@gmail.com
\end{abstract}

\begin{abstract}
Abstrak
Pada hakikatnya manusia itu diciptakan Tuhan sebagai makhluk sempurna, sehingga mampu mencintai dirinya, mencintai orang lain beda jenis, maupun yang sejenis, sehingga kemungkinan terjadi perilaku menyimpang dalam perilaku seksual. Penelitian ini bertujuan mengetahui Hubungan antara aspek-aspek pengontrolan diri dengan perilaku seksual, dan menilai seberapa besar pengaruh dari pengontrolan diri terhadap berperilaku seksual pada Gay. Penelitian ini menggunakan rancangan Cross Sectional Study. Data di analisis menggunakan uji Chi-Square dan uji multiple logistik regression. Hasil penelitian menunjukan bahwa kontrol pengetahuan tidak berpengaruh terhadap 5 komponen perilaku seksual. Kontrol perilaku hanya berpengaruh terhadap 1 komponen perilaku seksual saja yaitu perilaku anal seks, dengan nilai $p=0,007(p<0,05)$, nilai $\mathrm{OR}=7,636$ $(\mathrm{OR} \geq 1)$, nilai $\mathrm{CI}=1,736(\mathrm{CI} \geq 1)$. Kontrol keputusan hanya berpengaruh terhadap 1 komponen perilaku seksual saja yaitu perilaku petting, dengan nilai $\mathrm{p}=0,047(\mathrm{p}<0,05)$, nilai $\mathrm{OR}=4,133(\mathrm{OR} \geq 1)$, nilai $\mathrm{CI}=1,020(\mathrm{CI} \geq 1)$.
\end{abstract}

Kata kunci: Perilaku, Keputusan, Petting, Anal Seks.

\begin{abstract}
In essence, God creates man as a perfecct being, so as to love himself, love others different types, or similar, so the possibility of misconduct in sexual behavior. This study aimed to determine the relationship between aspects of self control sexual behavior, and assess the extent of the influence of controlling themselves against sexual behavior on gay. The study design uses cross sectional study. Data were analyzed using Chi-square test and multiple logistic regression. The results showed that the control of knowledge does not affect the 5 components of sexual behavior that was only anal sex behavior, with a value of $p=0,007(p<0,05)$, the value of OR $=7,636$ $(O R \geq 1), C I=1,736(C I \geq)$. Control decision affects only one component of sexual behavior that is only petting behavior, with a value of $p=0,047(p<0,05)$, the value of $O R=4,133(O R \geq 1), C I=1,020(C I \geq 1)$.
\end{abstract}

Keywords: Behavior, Decision, Petting, Anal Sex. 


\section{PENDAHULUAN}

Penyimpangan seksual adalah aktivitas seksual yang ditempuh seseorang untuk mendapatkan kenikmatan seksual dengan tidak sewajarnya. Biasanya, cara yang digunakan oleh orang tersebut adalah menggunakan obyek seks yang tidak wajar. Penyebab terjadinya kelainan ini bersifat psikologis atau kejiwaan, yang di peroleh dari pengalaman sewaktu kecil, maupun dari lingkungan pergaulan, dan faktor genetic (Kelly Brook, 2001). Jumlah penganut homoseksual termasuk LGBT di Indonesia dari waktu ke waktu semakin meningkat. Peningkatan itu terjadi karena mereka lebih membuka diri atau coming out (mengaku). Mereka merasa berani mengaku karena gaya hidup gay menjadi pilihan dan tidak mengganggu orang lain. Bahkan, mereka keluar secara berkelompok dan menunjukan status mereka ke publik (Azhari, 2008).

Telah tercatat ada 22 negara dari 204 negara yang telah diakui secara de facto oleh PBB yang melegalkan pernikahan sesama jenis secara penuh di seluruh wilayah negaranya. Freedom to Marry Organization, 2014 ke 22 negara itu ialah: Norwegia (1993), Belanda (1996), Belgia (2003), Spanyol (2005), Kanada (2005), Afrika Selatan (2006), Swedia (2008), Portugal (2009), Meksiko (2009), Islandia (2010), Argentina (2010), Uruguay (2010), Selandia Baru (2013), Perancis (2013), Denmark (2013), Inggris dan Wales (2013), Brazil (14 mei 2013),Skotlandia (2014), Luksemburg (18 Juni 2014), Finlandia (28 November 2014), Irlandia (23 Mei 2015), Amerika Serikat (26 Juni 2015) (Chester, 2016).

Berdasarkan estimasi Kemenkes pada tahun 2012, terdapat 1.095.970 LSL baik yang tampak maupun tidak. Jawa Barat merupakan provinsi dengan jumlah LSL terbanyak. Sebanyak 300.198 orang yang terindikasi merupakan gay. Sementara itu, Jawa Tengah memiliki penderita gay dengan jumlah 218.227. (http://www.pusdatin.kemkes.go.id), di akses tanggal 05 februari 2018). Di kota bau-bau jumlah gay pada tahun 2016 berjumlah 442 orang (waria 78 orang dan LSL 364 orang). Pada periode tahun 2017 berjumlah 552 orang (waria 86 orang dan LSL 466 orang) (wawancara dengan $M$. Arafah Basaru, Direktur Lembaga Advokasi HIV/AIDS Bau-Bau, di ambil pada tanggal 10 februari 2018).

Pria memiliki tingkat permisivitas 5 kali lebih besar dibandingkan wanita dalam hubungan seksual. Oleh karena itu, jika penelitian ini dikorelasikan dengan perilaku seksual permisif pada gay, maka adanya kemungkinan bahwa mereka juga memiliki perilaku seksual yang permisif berkaitan dengan hasil penelitian yang mengungkap bahwa pria memiliki tingkat permisivitas yang lebih besar berkaitan dengan faktor gender (Widyastuti, 2009).

secara garis besar perilaku seksual tidak hanya terletak pada faktor eksternal seperti lingkungan dan pergaulan saja, namun juga berkaitan dengan faktor internal atau berasal dari diri individu itu sendiri, salah satunya adalah kontrol diri (Suwarti, 2010).

Jika seseorang gay memiliki kontrol diri yang baik, maka individu tersebut juga memiliki kontrol terhadap perilaku seksualnya, sebaliknya saat individu memiliki kontrol diri yang rendah maka akan semakin tinggi tingkatan perilaku seksualnya. Lebih lanjut hal ini berkaitan dengan pembawaan konsekuensi yang positif kepada diri kaum pria homoseksual saat mereka memiliki kontrol diri yang tinggi dan perilaku seksual yang terkontrol. Berlandaskan semua keterangan tersebut maka tujuan dari penelitian ini adalah untuk mengetahui dan mengukur secara empiris hubungan aspek - aspek kontrol diri dengan perilaku seksual pada gay.

\section{BAHAN DAN METODE Lokasi dan Rancangan Penelitian}

Penelitian ini di lakukan diwilayah kota Bau-bau Provinsi Sulawesi Tenggara. Jenis penelitian yang di gunakan adalah penelitian kuantitatif dengan menggunakan desain Cross Secrional Study. 


\section{Populasi dan Sampel}

Populasi dalam penelitian ini adalah seluruh jumlah gay pada 1 tahun terakhir periode januari - desember 2017. Sampel sebanyak 51 orang yang di pilih secara purposive sampling yang telah memenuhi kriteri inklusi, yaitu: waria dan LSL yang tinggal di kota Bau-bau, waria yang tercatat memiliki data di lembaga LAHA Bau-bau, waria dan LSL yang hanya tertarik secara seksual terhadap laki-laki (tidak tertarik terhadap perempuan), waria dan LSL yang bersedia menjadi sampel dalam penelitian ini.

\section{Metode Pengumpulan Data}

Metode pengumpulan data dalam penelitian ini adalah dengan menggunakan kuesioner. Skala pengukuran yang di gunakan adalah skala likert, yang di gunakan untuk mengukur hasil jawaban atau pendapat responden dengan 5 pilihan jawaban yang memiliki tingkatan skor yang berbeda.

\section{Analisis data}

Uji validitas digunakan untuk mengukur sah atau valid tidaknya suatu kuesioner. Suatu kuesioner dikatakan valid jika pertanyaan pada kuesioner mampu untuk mengungkapkan sesuatu yang akan diukur oleh kuesioner tersebut. Uji validasi data dalam penelitian ini menggunakan software SPSS, dengan nilai $\mathrm{P}=0,05$. Pertanyaan dalam kuesioner di katakan valid jika nilai sig (2-taled) kurang dari 0,05 . Kriteria yang digunakan untuk menyatakan suatu instrument penelitian dikatakan reliable jika memberikan nilai Cronbach Alpha $(\alpha)$ lebih besar dari pada 0,8 .

Metode analisis data yang digunakan untuk menjawab rumusan masalah dalam penelitian ini adalah multiple logistic regression. Regresi linier berganda bertujuan untuk mengetahui seberapa besar pengaruh aspek-aspek pengontrolan diri terhadap perilaku seksual pada gay.

\section{HASIL}

Hasil penelitian menunjukan antara komponen kontrol diri yang pertama yaitu kontrol pengetahuan dengan 5 komponen perilaku seksual di peroleh hubungan negatif. Koefisien dari kontrol pengetahuan dengan hugging di peroleh nilai $\mathrm{p}$ sebesar 0,197 $(\mathrm{P}<0,05)$, dengan kissing di peroleh nilai $\mathrm{p}$ sebesar $0,080 \quad(\mathrm{P}<0,05)$, dengan petting di peroleh nilai $\mathrm{p}$ sebesar 0,570 $(\mathrm{P}<0,05)$, dengan oral seks di peroleh nilai $\mathrm{p}$ sebesar $0,136(\mathrm{P}<0,05)$, dengan anal seks di peroleh nilai $\mathrm{p}$ sebesar $0,700(\mathrm{P}<0,05)$. Hal ini menunjukan bahwa semakin baik kontrol pengetahuan maka di ikuti dengan semakin sering dilakukannya 5 komponen perilaku seksual.

Berdasarkan analisis data dari komponen kontrol diri yang kedua yaitu kontrol perilaku dengan 5 komponen perilaku seksual diperoleh hubungan negatif, kecuali dengan komponen perilaku anal seks. koefisien dari kontrol perilaku dengan hugging di peroleh nilai $\mathrm{p}$ sebesar $1,000(\mathrm{P}<0,05)$, dengan kissing di peroleh nilai $\mathrm{p}$ sebesar $0,903 \quad(\mathrm{P}<0,05)$, dengan petting di peroleh nilai $\mathrm{p}$ sebesar 0,464 $(\mathrm{P}<0,05)$, dengan oral seks di peroleh nilai p sebesar 0,303 $(\mathrm{P}<0,05)$.

Berdasarkan analisis data dari komponen kontrol diri yang ketiga di yaitu kontrol keputusan dengan 5 komponen perilaku seksual di peroleh hubungan negarif, kecuali dengan komponen petting. Koefisien dari kontrol keputusan dengan hugging di peroleh nilai $\mathrm{p}$ sebesar 0,901 $(\mathrm{P}<0,05)$, dengan kissing di peroleh nilai $\mathrm{p}$ sebesar $0,665(\mathrm{P}<0,05)$, dengan oral seks di peroleh nilai $\mathrm{p}$ sebesar $0,983 \quad(\mathrm{P}<0,05)$, dengan anal seks di peroleh nilai $\mathrm{p}$ sebesar $0,309(\mathrm{P}<0,05)$.

\section{PEMBAHASAN}

Kontrol perilaku memiliki hubungan yang bermakna dengan perilaku anal seks, atau dapat dikatakan bahwa semakin baik kontrol perilaku nya maka semakin jarang pula perilaku anal seksnya. Hal ini di karenakan perilaku anal seks adalah memasukan alat kelamin ke dalam lubang anal/dubur pasangan seksual dimana pada yang baru pertama kali melakukan nya akan merasakan kesakitan (pada yang berperilaku sebagai perempuan), sehingga 
banyak yang tidak melakukan perilaku ini. Kecuali karena terpaksa dari pasangan seksual nya. Perilaku petting memiliki hubungan yang bermakna dengan kontrol keputusan atau dapat di katakan semakin baik kontrol keputusan maka semakin jarang pula dilakukannya perilaku seksual petting karena perilaku petting bukan perilaku yang berat di bandingkan dengan perilaku seksual lainnya.

Hasil penelitian ini menunjukan fakta bahwa semakin rendah kontrol diri, maka akan semakin tinggi perilaku seksual. Hal ini sejalan dengan penelitian dari Jazuli (2008) yang menyebutkan bahwa adanya hubungan negative antara kontrol diri dengan perilaku seksual, dimana saat perilaku seksual rendah maka individu tersebut memiliki kontrol diri yang tinggi, atau sebaliknya.

Hurlock (dalam Ghufron \& Risnawati, 2010) menjelaskan bahwa kontrol diri berkaitan dengan bagaimana individu mengendalikan emosi serta dorongan-dorongan dari dalam dirinya. Oleh karena itu saat seseorang memiliki kontrol terhadap dorongan-dorongan seksual dari dalam diri maupun yang datang dari luar maka individu tersebut memiliki kontrol pula terhadap perilaku seksualnya sehingga mencegah terjadinya perilaku permisif dalam perilaku seksualnya.

Dari sisi seks anal, mereka yang memiliki kontrol diri terhadap perilaku seksualnya yang lebih rendah dilaporkan lebih sering mendapatkan seks anal dibanding dengan mereka yang memiliki kontrol seksual yang lebih baik. Hal ini sesuai dengan pendapat dari Ghufron dan Risnawati (2010), yang menyatakan bahwa semakin tinggi kontrol diri semakin baik pengendalian terhadap tingkah laku.

\section{KESIMPULAN DAN SARAN}

semakin baik kontrol pengetahuannya maka di ikuti dengan semakin sering dilakukannya lima jenis perilaku seksual. semakin baik kontrol perilakunya maka semakin jarang pula dilakukannya perilaku anal seks. dan semakin baik kontrol keputusan maka semakin jarang pula dilakukannya perilaku seksual petting. Individu gay perlu mengembangkan kontrol diri yang baik dalam semua komponennya, baik itu kontrol pengetahuan, kontrol perilaku, dan kontrol keputusan yang di dapatkan dari pemahaman agama yang baik sejak dini, dan dukungan lingkungan keluarga yang baik. Pemahaman lebih lanjut mengenai perilaku seks dapat dilakukan agar pria gay dapat menyadari risiko yang dapat diterima sehingga mampu meningkatkan kontrol dirinya dalam berbagai situasi yang kontekstual dengan seksualitas gay. Di sarankan agar pada penelitian selanjutnya, agar saat akan melakukan penelitian datang bersama dengan salah satu atau bagian dari mereka untuk memudahkan berkomunikasi dengan sampel penelitian.

\section{DAFTAR PUSTAKA}

Azhari Rama dan Putra Kencana. (2008) Membongkar Rahasia Jaringan Cinta Terlarang Kaum Homoseksual. Jakarta: Hujah Press.

Basaru M. Arafah. (2018). Direktur Lembaga Advokasi HIV/AIDS. BauBau. Wawancara di lakukan pada tanggal 10 februari 2018.

Brook Kelly. (2001). Education of Sexuality for Teenager. North Carolina: Charm press.

Chester, M. R., Sinnard, M. T., Rochlen, A. B., Nadeau, M. M., Balsan, M. J., \& Provence, M. M. (2016). Gay men's experiences coming out online: A qualitative study. Journal of Gay and Lesbian Social Services, 28(4), 317$335 . \quad$ https://doi.org/10. 1080/10538720.2016.1221785

Dean, T. (2009). Unlimited intimacy: Reflections on the subculture of barebacking. London: The University of Chicago Press

Ghufron, M.N. \& Risnawati, R.S. (2010). Teori-teori psikologi. Yogyakarta: Ar-ruzz Media.

Http://www.pusdatin.kemkes.go.id. (2014). Di akses tanggal 5 februari 2018.

Jazuli, A.S. (2008). Perilaku seksual remaja ditinjau dari kontrol diri dan 
pengetahuan seksualitas dalam materi fiqh di pondok pesantran pelajar. Skripsi (tidak di terbitkan). Surakarta: Fakultas Psikologi Universitas Muhammadiyah.

Suwarti. (2010). Pengaruh kontrol diri terhadap perilaku seksual remaja ditinjau dari jenis kelamin pada siswa SMA di purwokerto. Sainteks Jurnal Penelitian, 6, 37-46.

Widyastuti, E.S.A. (2009). Factor personal dan social yang mempengaruhi sekap remaja terhadap sikap hubungan seks pranikah: sebuah studi di lokalisasi Sunan Kuning dan Gamilangu Semarang. Tesis (tidak diterbitkan). Semarang: Fakultas Kesehatan Universitas Diponegoro.

Journal of Multidisciplinary Research, 2(2): 291-300

Simanungkalit E.V. (2012). Analisis kualitas kehidupan kerja karyawan industri garmen di Indonesia (Tesis). Jakarta: Universitas Indonesia.

Sirgy M., Efraty D., Siegel P., \& Lee D.J. (2001). A new measure of quality of working life (QWL) based on need satisfaction and spillover theories. Social Indicators Research, 55 (3): 241-302

Srivastava S, \& Kanpur R. (2014). A study on quality of work life: key elements \& it's implications. IOSR Journal of Business and Management, 16 (3): 54-59.

Swamy D.R, Nanjundeswaraswamy T.S, \& Rashmi S. (2015). Quality of Work Life: Scale Development and Validation. International Journal of Caring Sciences, 8(2): 281-300

Taghavi S., Ebrahimzadeh F., Bhramzadh H. \&Masoumeh H. (2014). A study of the relationship between quality of work life and performance effectiveness of high school teachers' in Shirvan. International Journal of Academic Research in Business and Social Sciences, 4(1): 295-301 